\title{
Sensitivity to systemic therapy for metastatic breast cancer in CHEK2 1100delC mutation carriers
}

\author{
Mieke Kriege $^{1}$ - Agnes Jager ${ }^{1}$ Antoinette Hollestelle ${ }^{1}$ Els M. J. J. Berns ${ }^{1}$. \\ Jannet Blom ${ }^{1}$ • Marion E. Meijer-van Gelder ${ }^{1}$ • Anieta M. Sieuwerts ${ }^{1}$. \\ Ans van den Ouweland ${ }^{2} \cdot$ J. Margriet Collée ${ }^{2} \cdot J_{\text {Judith R. Kroep }}$ • \\ John W. M. Martens ${ }^{1} \cdot$ Maartje J. Hooning ${ }^{1}$ Caroline Seynaeve ${ }^{1}$
}

Received: 26 March 2015 / Accepted: 24 April 2015 / Published online: 10 May 2015 (C) The Author(s) 2015. This article is published with open access at Springerlink.com

\begin{abstract}
Purpose The role of CHEK2 in DNA repair by homologous recombination suggests that $C H E K 2$-associated breast cancer (BC) patients might be more sensitive to chemotherapy inducing double-strand DNA breaks, but results hereon are lacking. We compared the sensitivity to first-line chemotherapy and endocrine therapy between CHEK2 1100delC and non-CHEK2 metastatic breast cancer (MBC) patients. Methods Sixty-two CHEK2 1100delC MBC patients were selected from three cohorts genotyped for CHEK2 $1100 \mathrm{delC}$ (one non-BRCAl/2 cohort and two sporadic cohorts). Controls were 62 non-CHEK2 MBC patients, matched for age at and year of primary $\mathrm{BC}$ diagnosis, and year of metastatic disease. Objective response rate (complete and partial response) to, and progression-free survival (PFS) and overall survival (OS) after start of firstline chemotherapy and endocrine therapy were compared between $C H E K 2$ and non-CHEK2 patients.

Results Median age at $\mathrm{BC}$ diagnosis was 46 and 51 years at MBC diagnosis. First-line chemotherapy consisted of anthracycline-based chemotherapy $(n=73)$, taxanes $(n=16), \mathrm{CMF}(-$ like $)$ chemotherapy $(n=33)$ and taxane/ anthracycline regimens $(n=2)$. CHEK2 and non-CHEK2 patients had a comparable objective response rate (44 vs.
\end{abstract}

Mieke Kriege

a.kriege@erasmusmc.nl

1 Department of Medical Oncology, Erasmus MC Cancer Institute, Groene Hilledijk 301, 3075 EA Rotterdam, The Netherlands

2 Departments of Clinical Genetics, Erasmus MC Cancer Institute, Rotterdam, The Netherlands

3 Department of Clinical Oncology, Leiden University Medical Centre, Leiden, The Netherlands
$52 \%$ ). Also, PFS and OS after start of chemotherapy were comparable between both patient groups (hazard ratio $0.91 ; 95 \%$ confidence interval $0.63-1.30$ and $1.03 ; 95 \%$ CI $0.71-1.49$, respectively). Thirty-six CHEK2 and 32 non-CHEK2 patients received first-line endocrine therapy (mainly tamoxifen) for MBC. No significant differences were observed in objective response rate to, and PFS and OS after start of endocrine therapy.

Conclusion No differential efficacy of chemotherapy and endocrine therapy given for MBC was observed in CHEK2 versus non-CHEK2 patients.

Keywords Metastatic breast cancer - CHEK2 1100delC . Chemotherapy $\cdot$ Endocrine therapy $\cdot$ Response $\cdot$ Survival

\section{Introduction}

CHEK2 is a tumor suppressor gene associated with a moderately increased cumulative lifetime breast cancer (BC) risk (1.4- to 3-fold; Cybulski et al. 2011; MeijersHeijboer et al. 2002; Weischer et al. 2008). The CHEK2 gene encodes for the protein kinase CHEK2 which plays a critical role in cell cycle control and DNA damage repair. In response to double-strand DNA breaks, CHEK2 is activated by ataxia telangiectasia mutated (ATM) and is involved in cell cycle control, DNA repair and apoptosis. CHEK2 kinase phosphorylates TP53 and BRCA1, whereupon BRCA1 represses the non-homologous end-joining pathway and activates the homologous recombination repair pathway (Nevanlinna and Bartek 2006; Roeb et al. 2012; Tung and Silver 2011). Different CHEK2 variants have been described, and in the Netherlands, the prevalence of the CHEK2 1100delC variant is relatively high, while other CHEK2 variants (IVS2 $+1 \mathrm{G}>\mathrm{A}$, del5395, 1157T) 
are very rare (The CHEK2 Breast Cancer Case Control Consortium 2004; Hollestelle et al. 2010; Meijers-Heijboer et al. 2002).

BC patients carrying the germline CHEK2 1100delC mutation mainly develop estrogen receptor (ER)-positive BC (de Bock et al. 2006; Nagel et al. 2012; Weischer et al. 2012) and have an twofold to threefold increased risk of developing contralateral BC. Moreover, a worse distant disease-free survival and overall survival (OS) for CHEK2 1100delC BC patients have been reported (de Bock et al. 2004; Kriege et al. 2014; Schmidt et al. 2007; Weischer et al. 2012). A plausible explanation for the worse survival might be a decreased sensitivity to (adjuvant) systemic therapy in CHEK2 compared to non-CHEK2 BC patients. On the other hand, the function of the CHEK2 protein kinase in the repair of double-strand DNA breaks suggests that BC patients carrying a CHEK2 mutation might have an increased sensitivity to chemotherapeutic agents causing double-strand DNA breaks, such as platinum, alkylating agents and/or anthracyclines (Nevanlinna and Bartek 2006). However, data on the efficacy of systemic therapy in CHEK2-associated BC patients are very limited so far. In a previous study of our group regarding distant disease-free survival and breast cancer-specific survival of primary BC, no differential effect of adjuvant chemotherapy or endocrine therapy was observed in CHEK2 1100delC compared with non-CHEK2 breast cancer patients (Kriege et al. 2014).

To further elucidate the potentially differential efficacy of systemic therapy among CHEK2 mutation carriers compared to non-CHEK2 patients, we assessed the efficacy of standard first-line chemotherapy given for metastatic breast cancer (MBC) in CHEK2 1100delC compared with non-CHEK2 patients. Furthermore, the efficacy of first-line endocrine therapy for MBC was also determined in both groups.

\section{Patients and methods}

For the current study, we used a database available from a previous study (Kriege et al. 2014), consisting of women with invasive BC genotyped for CHEK2 1100delC from three different cohorts. One cohort consisted of nonBRCA1/2 patients from the Rotterdam Family Cancer Clinic (non-BRCA1/2 cohort). The two other cohorts consisted of sporadic BC patients from (1) the ORIGO study, a study designed to investigate the prevalence of $B R C A 1 / 2$ mutations in an unselected BC population (ORIGO cohort) and (2) the Rotterdam Medical Oncology Tumor Bank database (RMOT cohort). More details regarding these cohorts have previously been described (Kriege et al. 2014). The inclusion criteria for the previous study were first BC diagnosed before age 80 and after 1970, and follow-up data available. Patients with a proven BRCAl or
BRCA2 mutation were excluded. For the current study, BC patients with a CHEK2 1100delC mutation and treated with first-line chemotherapy (irrespective of type) for metastatic disease were selected from the database.

The CHEK2 1100delC mutation status of the respective $\mathrm{BC}$ patients in the three cohorts was determined by either allele-specific oligonucleotide hybridization or Taqman genotyping as described earlier. DNA was isolated from peripheral blood of patients from the non-BRCAl/2 and ORIGO cohorts and from freshly frozen tumor tissue of patients from the RMOT cohort as described (Kriege et al. 2014). In this paper, we refer to CHEK2 1100 delC mutation carriers as $C H E K 2$ mutation carriers.

In total, 4854 patients were tested for CHEK2 1100delC. From this cohort, $199(4.1 \%)$ had a CHEK2 1100delC mutation of whom $90(45.2 \%)$ patients developed distant metastases (Fig. 1). From the 90 CHEK2 1100delC BC patients with distant metastases, 28 patients were excluded because they were not treated with chemotherapy for MBC $(n=22)$ or because information on treatment for MBC was incomplete $(n=6)$. The eventually 62 eligible $C H E K 2$ mutation carriers with MBC were matched (1:1) for age at and period of primary $\mathrm{BC}$ diagnosis (within 5 years) and year of diagnosis of metastatic disease (within 5 years) with non-CHEK2 patients treated with chemotherapy for MBC, selected from the same database.

This study was approved by the Medical Ethical Committee of the Erasmus MC, Rotterdam, the Netherlands (MEC 2009-344).

\section{Data collection}

For all CHEK2 and non-CHEK2 MBC patients included in the current study $(n=124)$, data were extracted from hospital charts concerning patient and tumor characteristics, (systemic) treatment for primary BC, and if applicable for contralateral $\mathrm{BC}$ and loco-regional recurrence, date and location of distant metastases, type of and response to treatment for metastatic disease, date of progressive disease during or after first-line therapy (chemotherapy and/ or endocrine therapy) for MBC and death. End date of the study was date of death, date of last medical contact or date of end of study (1-6-2013), whichever came first.

\section{Endpoints}

The endpoints in this study were objective response rate and clinical benefit rate to, and progression-free survival (PFS) and OS after start of first-line chemotherapy and first-line endocrine therapy for MBC. Objective response was defined as complete response (CR) or partial response (PR), and clinical benefit as objective response or stable disease $>6$ months, according to International Union 
Fig. 1 Flowchart for patient selection

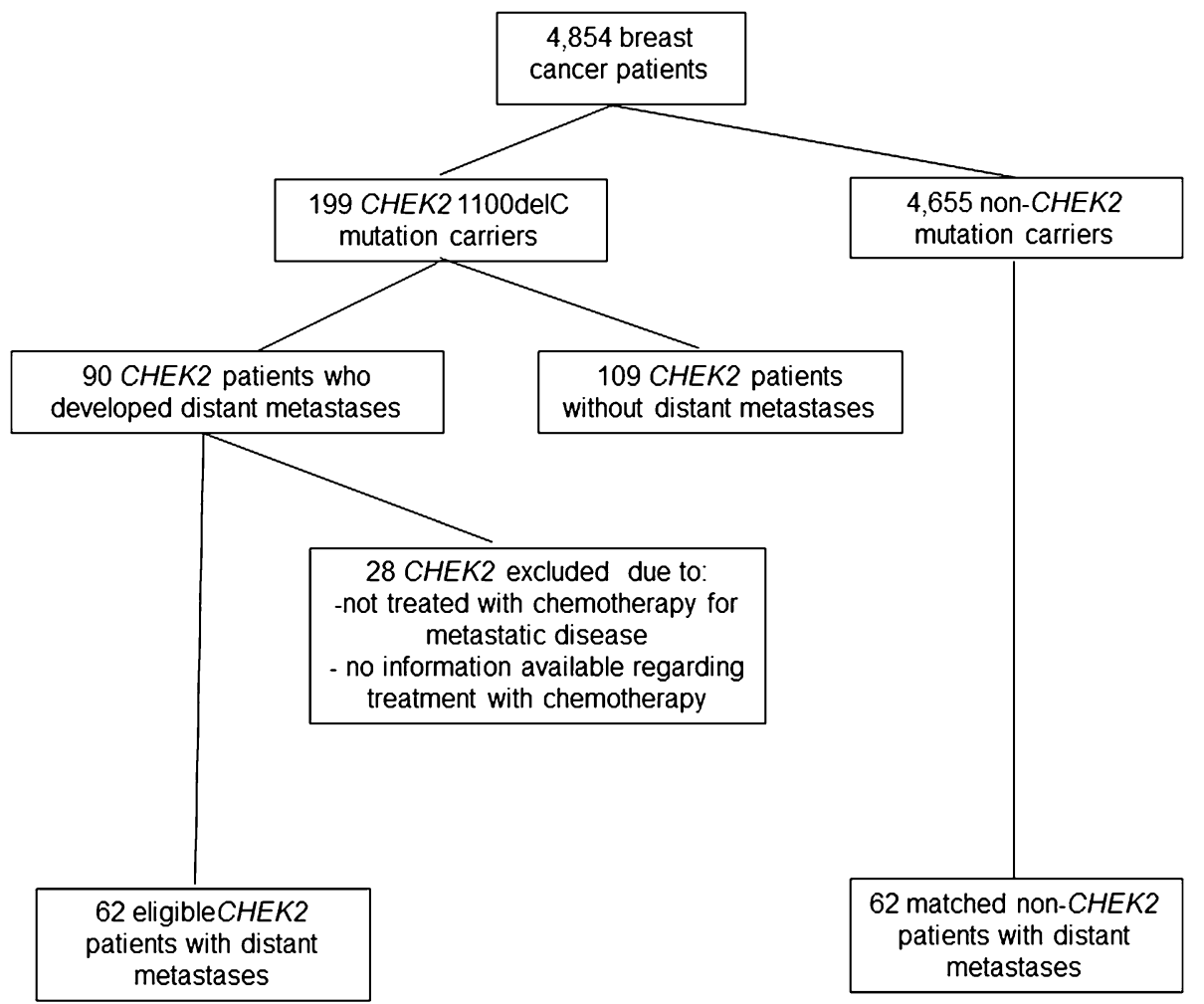

Against Cancer Criteria (Hayward et al. 1977), as a large part of the patient was treated before the introduction of the RECIST criteria in 2000. PFS after first-line systemic therapy (chemotherapy or endocrine therapy) was defined as time between start of either chemotherapy or endocrine therapy and date of progressive disease. OS after first-line systemic therapy (chemotherapy or endocrine therapy) was defined as time between start of either chemotherapy or endocrine therapy and death due to any reason [one patient (with a CHEK2 mutation) died from another reason than breast cancer (heart disease)].

For the study aims regarding the efficacy of first-line chemotherapy, all patients who received chemotherapy for $\mathrm{MBC}$ were included, irrespective of whether they also were treated with endocrine therapy for MBC before chemotherapy. Patients who were treated with an anthracycline-based regimen (without taxanes) as first-line chemotherapy were analyzed separately. For the analyses regarding the efficacy of endocrine therapy for $\mathrm{MBC}$, we only included patients receiving endocrine therapy before chemotherapy ( $n=68$; 36 CHEK2 and 32 non-CHEK2 patients), because endocrine therapy after chemotherapy was most times given as consolidation therapy.

\section{Statistical analyses}

Differences in patient, tumor and treatment characteristics between $C H E K 2$ and non-CHEK2 patients were tested by a Chi-square test or Fisher's exact test for categorical variables or by a $t$ test for continuous variables. Differences in response rate to first-line chemotherapy and to first-line endocrine therapy between the patient groups were tested by a Chi-square test with linear by linear association. The Kaplan-Meier method was used to calculate PFS and OS after start of first-line chemotherapy and first-line endocrine therapy. Censoring events were date of last medical contact or end date of the study. Differences in PFS and OS between $C H E K 2$ and non-CHEK2 patients were tested by a log-rank test. The Cox proportional hazard method was used to calculate univariate and multivariate hazard ratios (HR) and $95 \%$ confidence intervals (CI) for the risk of progression and death after start of first-line chemotherapy and after start of first-line endocrine therapy for $\mathrm{MBC}$ in CHEK2 versus non-CHEK2 patients. Potential confounders included in the multivariate model were as follows: age at diagnosis $(<50 ; \geq 50)$, ER status (negative; positive; unknown), adjuvant chemotherapy (yes; no), metachronous contralateral BC (yes; no), type of first distant metastases (soft tissue; bone; visceral) and distant disease-free interval ( $<2$ years; $\geq 2$ years) and for the models regarding chemotherapy also endocrine therapy for MBC before chemotherapy (yes; no) and time between first distant metastasis and start of first-line chemotherapy (continuous).

Two-sided $P$ values $<0.05$ were considered statistically significant. All analyses were performed with the use of SPSS software (version 21.0). 
Table 1 Patient, tumor and adjuvant treatment characteristics

\begin{tabular}{|c|c|c|c|c|c|}
\hline & \multicolumn{2}{|l|}{ CHEK2 } & \multicolumn{2}{|c|}{ Non-CHEK2 } & \multirow[t]{2}{*}{$P$} \\
\hline & $N$ & $\%$ & $N$ & $\%$ & \\
\hline Number of patients & 62 & & 62 & & \\
\hline $\begin{array}{l}\text { Median age at diagnosis } \\
\text { (years) }\end{array}$ & 45.4 & & 46.7 & & 0.76 \\
\hline Range & $25.5-67.1$ & & $24.0-67.5$ & & \\
\hline $\begin{array}{l}\text { Median age at diagnosis M1 } \\
\text { (years) }\end{array}$ & 51.0 & & 52.2 & & 0.69 \\
\hline Range & $30.0-69.2$ & & $27.7-68.7$ & & \\
\hline \multicolumn{6}{|l|}{ Year of diagnosis M1 } \\
\hline$<1990$ & 8 & 13 & 7 & 11 & 0.43 \\
\hline 1990-2000 & 30 & 48 & 26 & 42 & \\
\hline$\geq 2000$ & 24 & 39 & 29 & 47 & \\
\hline \multicolumn{6}{|l|}{ Tumor size } \\
\hline $\mathrm{T} 1$ & 24 & 41 & 13 & 22 & 0.05 \\
\hline $\mathrm{T} 2$ & 26 & 44 & 32 & 56 & \\
\hline $\mathrm{T} 3, \mathrm{~T} 4$ & 9 & 15 & 13 & 22 & \\
\hline Unknown & 3 & & 4 & & \\
\hline Node positive & 35 & 57 & 40 & 67 & 0.29 \\
\hline Not done/unknown & 1 & & 2 & & \\
\hline M1 at diagnosis & 3 & 5 & 2 & 3 & 1.00 \\
\hline \multicolumn{6}{|l|}{ Histologic grade } \\
\hline I & 8 & 18 & 5 & 10 & 0.33 \\
\hline II & 13 & 29 & 15 & 30 & \\
\hline III & 24 & 53 & 30 & 60 & \\
\hline Unknown & 17 & & 12 & & \\
\hline Estrogen receptor positive & 54 & 89 & 46 & 75 & 0.06 \\
\hline Unknown & 1 & & 1 & & \\
\hline $\begin{array}{l}\text { Progesterone receptor } \\
\text { positive }\end{array}$ & 42 & 79 & 36 & 67 & 0.14 \\
\hline \multicolumn{6}{|l|}{ Adjuvant chemotherapy* } \\
\hline No & 32 & 54 & 29 & 48 & 0.81 \\
\hline Anthracyclines & 17 & 29 & 19 & 32 & \\
\hline Other & 10 & 17 & 12 & 20 & \\
\hline Not applicable (M1) & 3 & & 2 & & \\
\hline \multicolumn{6}{|l|}{ Adjuvant endocrine therapy ${ }^{\mathrm{a}}$} \\
\hline No & 40 & 69 & 38 & 63 & 0.56 \\
\hline Yes & 18 & 31 & 22 & 37 & \\
\hline $\begin{array}{l}\text { Not applicable (M1) or } \\
\text { unknown }\end{array}$ & 4 & & 2 & & \\
\hline \multicolumn{6}{|l|}{ Contralateral breast cancer } \\
\hline Yes & 12 & 19 & 5 & 8 & 0.07 \\
\hline No & 50 & 81 & 57 & 92 & \\
\hline \multicolumn{6}{|l|}{ Distant disease-free interval } \\
\hline$\leq 1$ year & 7 & 11 & 6 & 10 & 0.93 \\
\hline $1-2$ years & 11 & 18 & 13 & 21 & \\
\hline $2-5$ years & 21 & 34 & 21 & 34 & \\
\hline$>5$ years & 23 & 37 & 22 & 35 & \\
\hline \multicolumn{6}{|l|}{ Site of first distant metastasis ${ }^{b}$} \\
\hline Soft tissue & 2 & 3 & 5 & 8 & 0.50 \\
\hline
\end{tabular}

Table 1 continued

\begin{tabular}{|c|c|c|c|c|c|}
\hline & \multicolumn{2}{|c|}{ CHEK2 } & \multicolumn{2}{|c|}{ Non-CHEK2 } & \multirow[t]{2}{*}{$P$} \\
\hline & $N$ & $\%$ & $N$ & $\%$ & \\
\hline Bone & 29 & 47 & 27 & 44 & \\
\hline Visceral & 31 & 50 & 30 & 48 & \\
\hline
\end{tabular}

\section{Results}

\section{Patient, tumor and treatment characteristics}

Patient, tumor and adjuvant treatment characteristics of CHEK2 1100delC and non-CHEK2 BC patients are depicted in Table 1 . The median age at primary BC diagnosis was 45.4 years for the CHEK2 mutation carriers and 46.7 years for the non- $C H E K 2$ patients, while the median age at the diagnosis of first distant metastases was 51.0 and 52.2 years, respectively. No significant differences in these tumor characteristics were observed between $\mathrm{CHEK} 2$ mutation carriers and non-CHEK2 patients. Tumors were mainly ER positive in both groups (89 and $75 \%$ in $C H E K 2$ and non-CHEK2 BC patients, respectively). Data regarding human epidermal growth factor receptor 2 (HER2) status are not mentioned, as these were mostly missing. First distant metastases occurred in bone for $47 \%$ of the mutation carriers and $44 \%$ of the non-CHEK2 patients, respectively, and in viscera for 50 and $48 \%$ of the patients, respectively.

\section{First-line chemotherapy}

Type of and response to first-line chemotherapy for MBC are shown in Table 2. First-line chemotherapy for MBC mainly consisted of anthracycline-based chemotherapy, being given to 34 (55\%) CHEK2 and 39 (63\%) nonCHEK2 patients, of whom 11 patients (six CHEK2 and five non-CHEK2) continued with $\mathrm{CMF}$ after the maximal cumulative anthracycline dose (data not shown). The number of patients receiving endocrine therapy after first-line chemotherapy (as consolidation therapy) was comparable for the CHEK2 mutation carriers $(n=18 ; 29 \%)$ and the non-CHEK2 patients $(n=16 ; 26 \%)$.

The objective response rate to first-line chemotherapy was similar for $C H E K 2$ and non-CHEK2 patients (42 and $44 \%$, respectively), and the clinical benefit rate was also similar in both groups $(77 \%)$. In the subgroup analysis of patients receiving an anthracycline-based regimen as firstline chemotherapy for $\mathrm{MBC}$, no significant differences in objective response rate (52 and $43 \%$, respectively) and 
Table 2 First-line chemotherapy for metastatic breast cancer

\begin{tabular}{|c|c|c|c|c|c|}
\hline & \multicolumn{2}{|c|}{ CHEK2 } & \multicolumn{2}{|c|}{ Non- $C H E K 2$} & \multirow[t]{2}{*}{$P$} \\
\hline & $N$ & $\%$ & $N$ & $\%$ & \\
\hline \multicolumn{6}{|l|}{ Type of chemotherapy } \\
\hline Anthracycline based ${ }^{\mathrm{a}}$ & 34 & 55 & 39 & 63 & \multirow[t]{4}{*}{0.25} \\
\hline Taxane based $^{\mathrm{b}}$ & 6 & 10 & 10 & 16 & \\
\hline Anthracycline/taxane regimen ${ }^{c}$ & 1 & 2 & 1 & 2 & \\
\hline CMF/CMF-like & 21 & 34 & 12 & 19 & \\
\hline \multicolumn{6}{|l|}{ Best response } \\
\hline Objective response & 27 & 44 & 32 & 52 & \multirow[t]{4}{*}{0.71} \\
\hline Stable disease & 21 & 35 & 18 & 29 & \\
\hline Progressive disease & 13 & 21 & 12 & 19 & \\
\hline Unknown & 1 & & & & \\
\hline Clinical benefit (objective response and stable disease $>6$ months) & 47 & 77 & 48 & 77 & 0.96 \\
\hline \multicolumn{6}{|l|}{ Progressive disease } \\
\hline During chemotherapy & 26 & 42 & 27 & 44 & \multirow[t]{4}{*}{0.92} \\
\hline After chemotherapy & & & & & \\
\hline No consolidation endocrine therapy & 18 & 29 & 19 & 31 & \\
\hline Consolidation endocrine therapy & 18 & 29 & 16 & 26 & \\
\hline \multicolumn{6}{|l|}{ Anthracycline-based therapy } \\
\hline Number of patients & 34 & & 39 & & \\
\hline \multicolumn{6}{|l|}{ Best response } \\
\hline Objective response & 18 & 52 & 17 & 43 & \multirow[t]{3}{*}{0.70} \\
\hline Stable disease & 8 & 24 & 12 & 31 & \\
\hline Progressive disease & 8 & 24 & 10 & 26 & \\
\hline Clinical benefit (objective response and stable disease $>6$ months) & 25 & 74 & 27 & 69 & 0.69 \\
\hline
\end{tabular}

$C M F$ cyclophosphamide, methotrexate and fluorouracil

${ }^{a}$ Anthracycline-based chemotherapy consisted of the following regimens: $19 \times \mathrm{FAC}, 14 \times \mathrm{FEC}, 3 \times \mathrm{AC}$ in the CHEK2 group (for three cases, the specific regimen was unknown) and $23 \times$ FAC, $7 \times$ FEC and $4 \times \mathrm{AC}$ in the non-CHEK2 group (FAC fluorouracil, adriamycin, cyclophosphamide, FEC fluorouracil, epirubicin, cyclophosphamide and $A C$ adriamycin, cyclophosphamide)

b Taxanes were given $2 \times$ in combination with trastuzumab in the CHEK2 group; and $3 \times$ in combination with trastuzumab, $1 \times$ in combination with bevacizumab, $1 \times$ in combination with trastuzumab and bevacizumab, $2 \times$ in combination with methotrexate in the non-CHEK2 group

${ }^{c}$ Anthracycline/taxane regimen consisted of adriamycin and docetaxel in the CHEK2 patient and of FAC followed by docetaxel in the non-CHEK2 patient clinical benefit rate (74 and $69 \%$, respectively) were observed between $C H E K 2$ mutation carriers and non-CHEK2 patients.

\section{PFS and OS after start of first-line chemotherapy}

Data on PFS and OS after start of first-line chemotherapy for $\mathrm{MBC}$ are shown in Table 3 and Fig. 2. CHEK2 and non-CHEK2 BC patients had a comparable 12-month PFS (28 vs. $32 \%$ ) and 12-month OS (64 vs. $76 \%$ ). Also, after adjusting for possible confounding factors (see method section), no significant differences in PFS (HR 0.91; $95 \%$ CI 0.63-1.30) and OS (HR 1.03; $95 \%$ CI 0.71-1.49) were observed between the $C H E K 2$ and non-CHEK2 groups. As PFS after start of first-line chemotherapy could have been influenced by consolidation endocrine therapy, we also performed the analyses for PFS, with censoring at date of start of consolidation endocrine therapy in respective patients. In these additional analyses, we observed no significantly different PFS between CHEK2 1100delC mutation carriers and non-CHEK2 patients (HR 0.92; $95 \%$ CI 0.63-1.52; data not shown).

Further, regarding the analyses for PFS for patients treated with anthracycline-based chemotherapy, no significant differences were observed between CHEK2 and nonCHEK2 BC patients (at 12 months 29 vs. $36 \%$, respectively; multivariate HR 0.92; $95 \%$ CI 0.57-1.48).

\section{First-line endocrine therapy}

Response to first-line endocrine therapy for $\mathrm{MBC}$ was evaluated in 36 CHEK2 1100delC and 32 non-CHEK2 patients (Table 4). The objective response rate was $14 \%$ in 
Table 3 Progression-free and overall survival after first-line chemotherapy

\begin{tabular}{|c|c|c|c|c|c|}
\hline & \multicolumn{2}{|l|}{ CHEK2 } & \multicolumn{2}{|c|}{$\begin{array}{l}\text { Non- } \\
\text { CHEK2 }\end{array}$} & \multirow[t]{2}{*}{$P$} \\
\hline & $N$ & $\%$ & $N$ & $\%$ & \\
\hline \multicolumn{6}{|l|}{ Progression-free survival } \\
\hline All chemotherapy & & & & & 0.84 \\
\hline 6 months & 41 & 66 & 42 & 68 & \\
\hline 12 months & 17 & 28 & 19 & 32 & \\
\hline 24 months & 5 & 8 & 2 & 3 & \\
\hline HR univariate $(95 \% \mathrm{CI})$ & $0.96(0.67-1.38)$ & & & & \\
\hline HR multivariate $(95 \% \mathrm{CI})^{\mathrm{a}}$ & $0.91(0.63-1.30)$ & & & & \\
\hline $\begin{array}{l}\text { Anthracycline-based } \\
\text { chemotherapy }\end{array}$ & & & & 0.92 & \\
\hline 6 months & 22 & 65 & 24 & 62 & \\
\hline 12 months & 10 & 29 & 13 & 36 & \\
\hline 24 months & 2 & 6 & 1 & 3 & \\
\hline HR univariate $(95 \% \mathrm{CI})$ & $0.98(0.61-1.56)$ & & & & \\
\hline HR multivariate $(95 \% \mathrm{CI})^{\mathrm{a}}$ & $0.92(0.57-1.48)$ & & & & \\
\hline Overall survival & & & & & 0.89 \\
\hline 6 months & 56 & 90 & 57 & 92 & \\
\hline 12 months & 39 & 64 & 46 & 76 & \\
\hline 24 months & 28 & 49 & 31 & 51 & \\
\hline 36 months & 14 & 24 & 14 & 28 & \\
\hline HR univariate $(95 \% \mathrm{CI})^{\mathrm{b}}$ & $1.03(0.71-1.49)$ & & & & \\
\hline
\end{tabular}

${ }^{\text {a }}$ Adjusted for distant disease-free interval

b None of the variables (age at diagnosis, ER status, adjuvant chemotherapy, metachronous contralateral breast cancer, type of first metastases, distant disease-free interval, endocrine therapy for metastatic disease before chemotherapy, time between first distant metastasis and start chemotherapy) had $>10 \%$ influence

CHEK2 mutation carriers and $19 \%$ in non-CHEK2 patients $(P=0.82)$. Also PFS (HR 1.50; $95 \%$ CI 0.90-2.49) and OS (multivariate HR 1.51; $95 \%$ CI 0.89-2.57) after start of first-line endocrine therapy were both not significantly different between $C H E K 2$ and non-CHEK2 BC patients.

\section{Discussion}

Currently, only a few biomarkers are used for therapy stratification in BC patients (e.g., ER, HER2), whereas biomarkers predictive of treatment response will contribute to further tailoring and improving $\mathrm{BC}$ treatment, i.e., avoiding toxic therapy for those not benefiting of it. Mutations in BC risk genes might be valuable markers for therapy response prediction, which already has been reported for BRCA1- and BRCA2-associated $\mathrm{BC}$, suggesting higher sensitivity to anthracyclines, platinum and potentially other agents (Bayraktar and Gluck 2012; Kriege et al. 2009; Tutt et al. 2010).

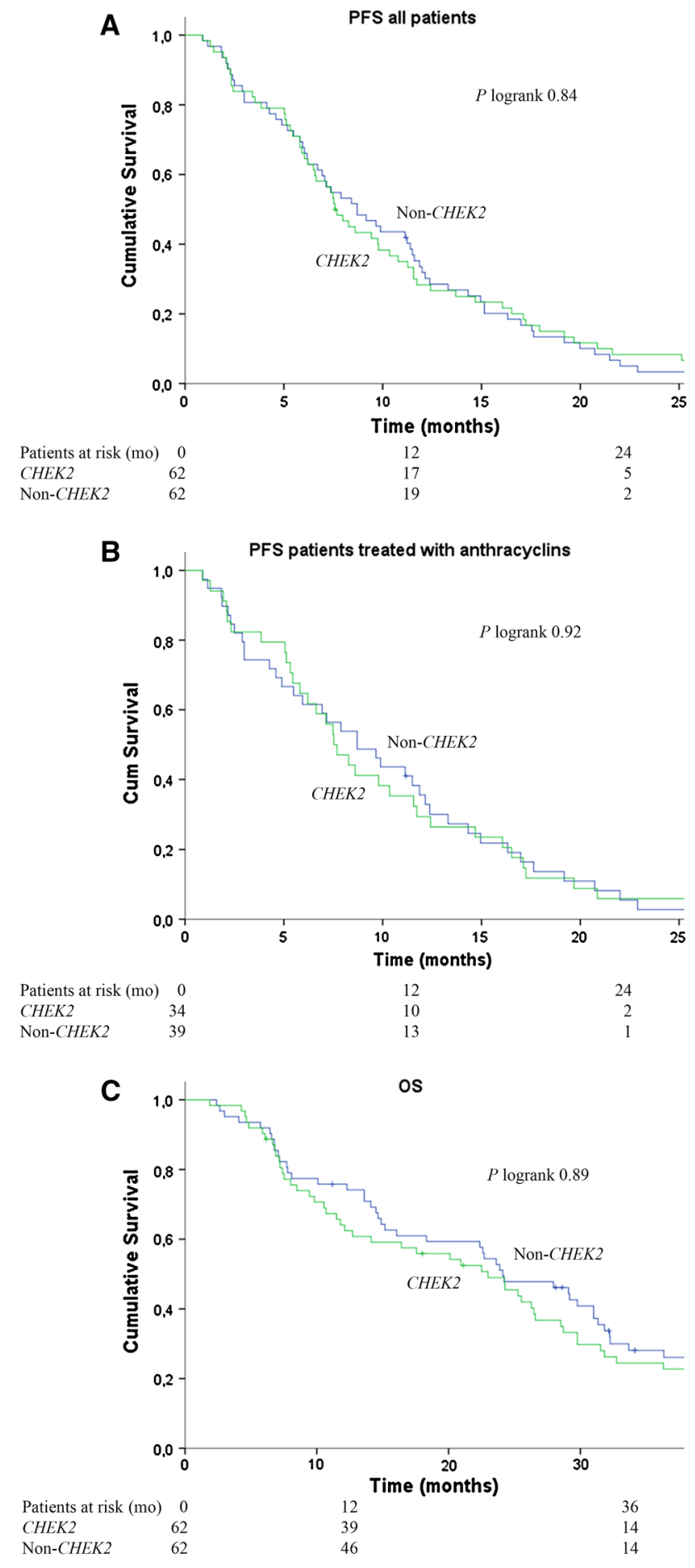

Fig. 2 Progression-free survival (PFS) in all metastatic breast cancer patients (a) and in metastatic breast cancer patients treated with anthracycline-based chemotherapy (b) and overall survival (OS) in metastatic breast cancer patients (c)

The current study is the first to address the response to systemic therapy in CHEK2 1100delC MBC patients. We observed a similar efficacy of first-line chemotherapy given for 
Table 4 First-line endocrine therapy for metastatic breast cancer

\begin{tabular}{|c|c|c|c|c|c|}
\hline & \multicolumn{2}{|c|}{ CHEK2 } & \multicolumn{2}{|c|}{ Non-CHEK2 } & \multirow[t]{2}{*}{$P$} \\
\hline & $N$ & $\%$ & $N$ & $\%$ & \\
\hline Number of patients & 36 & & 32 & & \\
\hline \multicolumn{6}{|c|}{ Type of endocrine therapy } \\
\hline Tamoxifen & 26 & 72 & 17 & 53 & 0.23 \\
\hline Aromatase inhibitor & 7 & 19 & 9 & 28 & \\
\hline Other & 3 & 8 & 6 & 19 & \\
\hline \multicolumn{6}{|l|}{ Best response } \\
\hline Objective response & 5 & 14 & 6 & 19 & 0.82 \\
\hline Stable disease & 18 & 52 & 14 & 45 & \\
\hline Progressive disease & 12 & 34 & 11 & 36 & \\
\hline Unknown & 1 & - & 1 & - & \\
\hline \multicolumn{6}{|c|}{ Progression-free survival } \\
\hline 6 months & 20 & 56 & 19 & 59 & 0.12 \\
\hline 12 months & 14 & 39 & 13 & 41 & \\
\hline 24 months & 3 & 8 & 6 & 19 & \\
\hline HR univariate ${ }^{\mathrm{a}}$ & 1.50 & $0.90-2.49$ & & & \\
\hline \multicolumn{6}{|l|}{ Overall survival } \\
\hline 6 months & 36 & 100 & 31 & 97 & 0.12 \\
\hline 12 months & 34 & 94 & 28 & 88 & \\
\hline 24 months & 26 & 78 & 26 & 81 & \\
\hline HR univariate ${ }^{\mathrm{a}}$ & 1.51 & $0.89-2.57$ & & & \\
\hline
\end{tabular}

${ }^{a}$ None of the added variables (age at diagnosis, ER status, adjuvant chemotherapy, metachronous contralateral breast cancer, type of first metastases, distant disease-free interval) had $>10 \%$ influence on the hazard ratio (HR); therefore, no multivariate HR was calculated

MBC in CHEK2 1100delC mutation carriers compared to nonCHEK2 patients. Both response rate to, and PFS and OS after start of first-line chemotherapy were similar in patients with and without the CHEK2 1100delC mutation. Also, in patients treated with anthracycline-based chemotherapy, no differential efficacy was observed between CHEK2 1100delC-associated and non-CHEK2 patients. These observations are in line with our previous findings concerning no differential effect of adjuvant chemotherapy on distant disease-free and breast cancerspecific survival in CHEK2 1100delC mutation carriers versus non-CHEK2 patients with early BC (Kriege et al. 2014).

An explanation for the lack of improved efficacy of anthracycline-based chemotherapy in CHEK2 mutation carriers compared with non-CHEK2 patients, as observed in the current study, might be that a proportion of the BCs diagnosed in CHEK2 1100delC mutation carriers are not driven by the loss of CHEK2 function, but still carry a wild-type $C H E K 2$ allele (either with or without loss of the mutant allele). Finally, the results might be due to the relatively small numbers ( 34 CHEK2 and 39 non-CHEK2 patients treated with anthracyclines).

Our observation regarding no differential efficacy of first-line endocrine therapy for MBC between CHEK2
$1100 \mathrm{delC}$ and non-CHEK2 patients is in line with the results of our previous study regarding no differential effect of adjuvant endocrine therapy on distant disease-free and BCSS in CHEK2 and non-CHEK2 early BC patients (Kriege et al. 2014). To our knowledge, there are no other reports on the efficacy of endocrine therapy in CHEK2 BC patients yet. In our opinion, however, the question is very relevant as the majority of $C H E K 2 \mathrm{BCs}$ is hormone sensitive at diagnosis (de Bock et al. 2004; Kriege et al. 2014; Schmidt et al. 2007; Weischer et al. 2012) and DNA diagnostics for CHEK2 have recently been implemented in the Netherlands (as part of genetic testing in the context of familial BC) and will be possibly impemented in other countries with a high prevalence. Although we included compared to other series a relative large number of CHEK2 metastatic breast cancer patients, the number of CHEK2 patients treated with endocrine therapy for MBC was small $(n=36)$, and future studies with larger sample sizes are needed to address this question further.

Results from the current study in MBC patients and our previous study in early $\mathrm{BC}$ patients regarding efficacy of chemotherapy and endocrine therapy do not explain the worse prognosis that has been reported for CHEK2 1100delC-associated compared with BC patients without this mutation (de Bock et al. 2004; Kriege et al. 2014; Schmidt et al. 2007; Weischer et al. 2012). Of note, this worse prognosis was not observed in all studies published in CHEK2 mutation carriers to date. A recent paper by Huzarski et al. (Huzarski et al. 2014) did not observe a worse survival in 487 CHEK2 mutation carriers from Poland; however, in this patient group, the majority of the patients had not the 1100delC, but another CHEK2 variant (Huzarski et al. 2014). Whether there is a difference between patients with these specific CHEK2 variants in response to (chemo)therapy and survival is unknown yet, although a different response to chemotherapy of different CHEK2 variants is suggested (Chrisanthar et al. 2008). This deserves further investigation which will require international collaboration as in the Netherlands mainly the CHEK2 1100delC mutation is prevalent.

Despite the unique results of the current paper, some limitations should be addressed. Patients included in the current study have been diagnosed and treated in different time periods, resulting in different treatment regimens used. In view of the small number of patients receiving a taxane as first-line chemotherapy for $\mathrm{MBC}$, no conclusions can be drawn for this type of chemotherapy for CHEK2 1100delC MBC patients. A second limitation in the analyses regarding the efficacy of chemotherapy is that in some patients, endocrine therapy was given as consolidation therapy after chemotherapy, potentially affecting PFS, but which is common practice in palliative care and outside of clinical trials. The number of patients treated with consolidation 
endocrine therapy, however, was comparable in the CHEK2 $(n=18)$ and the non-CHEK2 groups $(n=19)$. Furthermore, we performed analyses for PFS, with censoring at date of start of consolidation endocrine therapy in respective patients, showing similar results.

DNA diagnostics for hereditary breast cancer is recently extended with the CHEK2 gene in the Netherlands and in the near future potentially also in other countries having a relatively high prevalence of $C H E K 2$ mutations. In this view, results of the current study regarding the efficacy of systemic therapy in CHEK2 $1100 \mathrm{delC}$ mutation carriers are very relevant and may helpful with respect to counseling and treatment of respective patients.

In conclusion, the presence of a CHEK2 1100delC mutation has currently no impact on the choice of type of systemic treatment in respective MBC patients, neither for chemotherapy nor for endocrine therapy, and our findings do not explain the previously reported worse survival regarding CHEK2 1100delC BC. Our observations are important for the counseling and treatment of CHEK2 1100delC BC patients, as CHEK2 1100delC mutation testing is currently being offered in the Netherlands to familial $\mathrm{BC}$ families. On the other hand, the data underscore that further investigations for CHEK2 1100delC-associated BC in greater sample sizes, and other specific CHEK2 mutations, being more prevalent in other countries, are warranted aiming at increased knowledge and further personalized therapy.

Acknowledgments We thank Ellen Crepin and Petra Bos for data management and Bahar Ozturk, Vanja de Weerd, Anne van Galen and Cliff Maasbach for technical assistance. This study was supported by the Dutch Cancer Society, Grant DDHK 2009-4318.

Conflict of interest We declare that we have no conflict of interest.

Ethical statement This study was approved by the Medical Ethical Committee of the Erasmus MC, Rotterdam, the Netherlands (MEC 2009-344) and has been performed in accordance with the ethical standards laid down in the 1964 Declaration of Helsinki and its later amendments. For this type of study, formal consent is not required.

Open Access This article is distributed under the terms of the Creative Commons Attribution 4.0 International License (http://creativecommons.org/licenses/by/4.0/), which permits unrestricted use, distribution, and reproduction in any medium, provided you give appropriate credit to the original author(s) and the source, provide a link to the Creative Commons license, and indicate if changes were made.

\section{References}

Bayraktar S, Gluck S (2012) Systemic therapy options in BRCA mutation-associated breast cancer. Breast Cancer Res Treat 135:355-366

Chrisanthar R, Knappskog S, Lokkevik E, Anker G, Ostenstad B, Lundgren S, Berge EO, Risberg T, Mjaaland I, Maehle L,
Engebretsen LF, Lillehaug JR, Lonning PE (2008) CHEK2 mutations affecting kinase activity together with mutations in TP53 indicate a functional pathway associated with resistance to epirubicin in primary breast cancer. PLoS ONE 3:e3062

Cybulski C, Wokolorczyk D, Jakubowska A, Huzarski T, Byrski T, Gronwald J, Masojc B, Deebniak T, Gorski B, Blecharz P, Narod SA, Lubinski J (2011) Risk of breast cancer in women with a CHEK2 mutation with and without a family history of breast cancer. J Clin Oncol 29:3747-3752

de Bock GH, Schutte M, Krol-Warmerdam EM, Seynaeve C, Blom J, Brekelmans CT, Meijers-Heijboer H, van Asperen CJ, Cornelisse CJ, Devilee P, Tollenaar RA, Klijn JG (2004) Tumour characteristics and prognosis of breast cancer patients carrying the germline CHEK2*1100delC variant. J Med Genet 41:731-735

de Bock GH, Mourits MJ, Schutte M, Krol-Warmerdam EM, Seynaeve C, Blom J, Brekelmans CT, Meijers-Heijboer H, van Asperen CJ, Cornelisse CJ, Devilee P, Tollenaar RA, Klijn JG (2006) Association between the CHEK2*1100delC germ line mutation and estrogen receptor status. Int J Gynecol Cancer 16(Suppl 2):552-555

Hayward JL, Carbone PP, Heuson JC, Kumaoka S, Segaloff A, Rubens RD (1977) Assessment of response to therapy in advanced breast cancer: a project of the programme on clinical oncology of the International Union against Cancer, Geneva, Switzerland. Cancer 39:1289-1294

Hollestelle A, Wasielewski M, Martens JWM, Schutte M (2010) Discovering moderate-risk breast cancer susceptibility genes. Curr Opin Genet Dev 20:268-276

Huzarski T, Cybulski C, Wokolorczyk D, Jakubowska A, Byrski T, Gronwald J, Domagala P, Szwiec M, Godlewski D, Kilar E, Marczyk E, Siolek M, Wisniowski R, Janiszewska H, Surdyka D, Sibilski R, Sun P, Lubinski J, Narod SA (2014) Survival from breast cancer in patients with CHEK2 mutations. Breast Cancer Res Treat 144:397-403

Kriege M, Seynaeve C, Meijers-Heijboer H, Collee JM, MenkePluymers MB, Bartels CC, Tilanus-Linthorst MM, Blom J, Huijskens E, Jager A, van den Ouweland A, van Geel B, Hooning MJ, Brekelmans CT, Klijn JG (2009) Sensitivity to firstline chemotherapy for metastatic breast cancer in BRCA1 and BRCA2 mutation carriers. J Clin Oncol 27:3764-3771

Kriege M, Hollestelle A, Jager A, Huijts PE, Berns EM, Sieuwerts AM, Meijer-van Gelder ME, Collee JM, Devilee P, Hooning MJ, Martens JW, Seynaeve C (2014) Survival and contralateral breast cancer in CHEK2 1100delC breast cancer patients: impact of adjuvant chemotherapy. Br J Cancer 111:1004-1013

Meijers-Heijboer H, van den Ouweland A, Klijn J, Wasielewski M, de Snoo A, Oldenburg R, Hollestelle A, Houben M, Crepin E, van Veghel-Plandsoen M, Elstrodt F, van Duijn C, Bartels C, Meijers C, Schutte M, McGuffog L, Thompson D, Easton D, Sodha N, Seal S, Barfoot R, Mangion J, Chang-Claude J, Eccles D, Eeles R, Evans DG, Houlston R, Murday V, Narod S, Peretz T, Peto J, Phelan C, Zhang HX, Szabo C, Devilee P, Goldgar D, Futreal PA, Nathanson KL, Weber B, Rahman N, Stratton MR, Consortium CH-BC (2002) Low-penetrance susceptibility to breast cancer due to CHEK2(*)1100delC in noncarriers of BRCA1 or BRCA2 mutations. Nat Genet 31:55-59

Nagel JHA, Peeters JK, Smid M, Sieuwerts AM, Wasielewski M, de Weerd V, Trapman-Jansen AMAC, van den Ouweland A, Bruggenwirth $\mathrm{H}$, van IJcken WFJ, Klijn JGM, van der Spek PJ, Foekens JA, Martens JWM, Schutte M, Meijers-Heijboer H (2012) Gene expression profiling assigns CHEK2 1100delC breast cancers to the luminal intrinsic subtypes. Breast Cancer Res Treat 132:439-448

Nevanlinna H, Bartek J (2006) The CHEK2 gene and inherited breast cancer susceptibility. Oncogene 25:5912-5919

Roeb W, Higgins J, King MC (2012) Response to DNA damage of CHEK2 missense mutations in familial breast cancer. Hum Mol Genet 21:2738-2744 
Schmidt MK, Tollenaar RA, de Kemp SR, Broeks A, Cornelisse CJ, Smit VT, Peterse JL, van Leeuwen FE, van't Veer LJ (2007) Breast cancer survival and tumor characteristics in premenopausal women carrying the CHEK $2 * 1100$ delC germline mutation. J Clin Oncol 25:64-69

The CHEK2 Breast Cancer Case Control Consortium (2004) CHEK $2 * 1100$ delC and susceptibility to breast cancer: a collaborative analysis involving 10,860 breast cancer cases and 9,065 controls from 10 studies. Am J Hum Genet 74:1175-1182

Tung N, Silver DP (2011) Chek2 DNA damage response pathway and inherited breast cancer risk. J Clin Oncol 29:3813-3815

Tutt A, Robson M, Garber JE, Domchek SM, Audeh MW, Weitzel JN, Friedlander M, Arun B, Loman N, Schmutzler RK, Wardley A, Mitchell G, Earl H, Wickens M, Carmichael J (2010) Oral poly(ADP-ribose) polymerase inhibitor olaparib in patients with BRCA1 or BRCA2 mutations and advanced breast cancer: a proof-of-concept trial. Lancet 376:235-244

Weischer M, Bojesen SE, Ellervik C, Tybjaerg-Hansen A, Nordestgaard BG (2008) CHEK2*1100delC genotyping for clinical assessment of breast cancer risk: meta-analyses of 26,000 patient cases and 27,000 controls. J Clin Oncol 26:542-548

Weischer M, Nordestgaard BG, Pharoah P, Bolla MK, Nevanlinna H, Van't Veer LJ, Garcia-Closas M, Hopper JL, Hall P, Andrulis IL, Devilee P, Fasching PA, Anton-Culver H, Lambrechts D, Hooning M, Cox A, Giles GG, Burwinkel B, Lindblom A, Couch FJ, Mannermaa A, Grenaker Alnaes G, John EM, Dork T, Flyger H, Dunning AM, Wang Q, Muranen TA, van Hien R, Figueroa J, Southey MC, Czene K, Knight JA, Tollenaar RA, Beckmann MW, Ziogas A, Christiaens MR, Collee JM, Reed MW, Severi G, Marme F, Margolin S, Olson JE, Kosma VM, Kristensen VN, Miron A, Bogdanova N, Shah M, Blomqvist C, Broeks A, Sherman M, Phillips KA, Li J, Liu J, Glendon G, Seynaeve C, Ekici AB, Leunen K, Kriege M, Cross SS, Baglietto L, Sohn C, Wang X, Kataja V, Borresen-Dale AL, Meyer A, Easton DF, Schmidt MK, Bojesen SE (2012) CHEK2*1100delC heterozygosity in women with breast cancer associated with early death, breast cancer-specific death, and increased risk of a second breast cancer. J Clin Oncol 30:4308-4316 